УДК [528:629.783]: 004

DOI $10.21661 / \mathrm{r}-118409$

\title{
А.С. Глазунов
}

\section{СПУТНИКОВЫЕ И КОМПЬЮТЕРНЫЕ ТЕХНОЛОГИИ ДЛЯ ПРИКЛАДНОЙ НАВИГАЦИИ}

Аннотация: в статье рассмотрены практические приёмы навигаџии с использованием GPS-навигаторов, топографических карт и интернета, которые могут помочь людям, увлечённым путешествиями (туристам, рыбакам, охотникам и профессионалам (геологам, геодезистам, топографам) надежнее находить дорогу к намеченным местам. Описаны приёмы навигащии с GPS-навигатором Garmin eTrex H. Описанная методика поможет также найти и обратный путь, исключая или значительно уменьшая возможность потери ориентировки на незнакомой местности. Благодаря GPS-навигатору упрощается передвижение по незнакомой местности даже при наличие топографической картыл. Использование компьютерной сети «Интернет» значительно расширяет возможности навигачии со спутниковым приемником. Благодаря оперативному отображению всех изменений местности и крупному масштабу спутниковых снимков улучшаются возможности нахождения пути к намеченной цели.

Ключевые слова: навигачия, GPS-навигатор, навигаџионные параметры, местоопределение, координаты, топографическая карта, маршрут, интернет.

\section{A.S. Glazunov \\ SATELLITE AND COMPUTER TECHNOLOGIES FOR APPLIED NAVIGATION}

Abstract: the article describes practical methods of navigation using GPS-navigators, topographic maps and the Internet, which can help people, interested in travelling (tourists, fishermen, hunters, and including professionals (geologists, surveyors, topographers) to reliably find their way to the target site. It also describes methods of navigation with a GPS-navigator Garmin eTrex H. The described technique will help 
to find the way back, eliminating or significantly reducing the possibility of the loss of orientation in unfamiliar terrain. Thanks to GPS-navigator it is easier to move on unfamiliar terrain, even with the presence of a topographic map. The «Internet» network significantly expands the possibilities of satellite navigation receiver. Due to the rapid display of all the changes of the area and the large scale of satellite imagery it is easier to find the way to the target.

Keywords: navigation, GPS-navigator, navigation parameters, positioning, coordinates, topographic map, directions, Internet.

Термин навига́ция (лат. navigatio, от латинского navigo - «плыву на судне») исторически означал [1;2]:

1. Мореплавание, судоходство.

2. Период времени в году, когда по местным (климатическим) условиям возможно судоходство.

3. Основной раздел судовождения, в котором разрабатываются теоретические обоснования и практические приёмы вождения судов.

Хотя термин «навигация» обозначал искусство мореплавания, но с течением времени это понятие расширялось. Появились такие разделы навигации как авиационная, космическая, спутниковая навигация. В широком смысле термин «навигация» можно понимать как умение определения местоположения и направления движения [1;2].

В последнее десятилетие широкое применение для целей местоопределения получили спутниковые технологии, различным аспектам применения которых посвящено масса публикаций [3-24]. Спутниковые навигационные системы NAVSTAR (GPS), ГЛОНАСС, ГАЛИЛЕО и др. позволяют в режиме реального времени определять как местоположение приемника, так и параметры движения, т.е. практически осуществлять навигацию.

Появление в открытой продаже навигационных приемников различных фирм позволило использовать это достижение науки и техники широким слоям 
населения. Любители путешествий: туристы, рыбаки, охотники, люди по большей части не имеющие специального образования, используют навигационные GPS- приёмники для практической навигации. Для пользования такими приёмниками достаточно изучить инструкцию. Это может позволить избежать таких неприятных ситуаций на малознакомой местности как потеря ориентировки и проблемы с выбором направления движения, особенно в тёмное время суток, при отсутствии видимых ориентиров и при неблагоприятных погодных условиях.

Можно привести практические примеры применения GPS-навигаторов. Мне приходилось на лодке выезжать на Сектинское озеро (Новосибирская область, Коченёвский район). Этот водоём имеет длину около 5 км и ширину примерно 4 км. Берега заболочены и поросли полосой тростника и камыша шириной 100-200 метров. Заросли тростника и камыша растут также в воде вдоль берега озера, перекрывая проход через них к берегу и горизонт, что затрудняет ориентировку. Проплыть на озеро и обратно к берегу можно только по прочищенным проходам, которые плохо видны с озера. Положение этих проходов необходимо знать тем точнее, чем хуже условия освещенности, т.е. в сумерках и темноте. Так, не сумев найти выход к берегу в темное время суток, автору приходилось ночевать на озере в лодке при отрицательной температуре. С появлением GPSнавигаторов в открытой продаже отыскание выхода к берегу значительно облегчилось. Можно было не спешить с возвращением с охоты и рыбалки. На примере модели Garmin eTrex H [25] можно показать последовательность действий для того, чтобы возвращение в исходный пункт было успешным. Для этого было необходимо зафиксировать координаты выхода на озеро в виде точки, а затем при возвращении определять направление движения к ней. На данной модели навигатора эта операция выполнялась следующим образом. Со страницы «меню» через пункт «отметка» (рис. 1) переходим к странице «отметка маршрутной точки» (рис. 2) и сохраняем в памяти навигатора координаты выхода на озеро в виде маршрутной точки. Для лучшей наглядности этой точке можно дать какое-либо имя, например «озеро». 
Для того, чтобы найти путь к точке, сохранённой в памяти навигатора переходим со страницы «меню» на страницу «точки» и, найдя нужную точку, выбираем пункт меню «иди к» (рис. 3).

\begin{tabular}{|c|}
\hline MEHFO \\
\hline B. DTRETKA \\
\hline Р то̆'нки \\
\hline ДЕР WAFШРУTH \\
\hline In_ETFK \\
\hline $\mathrm{Yr}_{\mathrm{M}}^{\mathrm{A}}$ HAOTF-KA \\
\hline 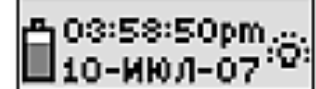 \\
\hline
\end{tabular}

Рис. 1

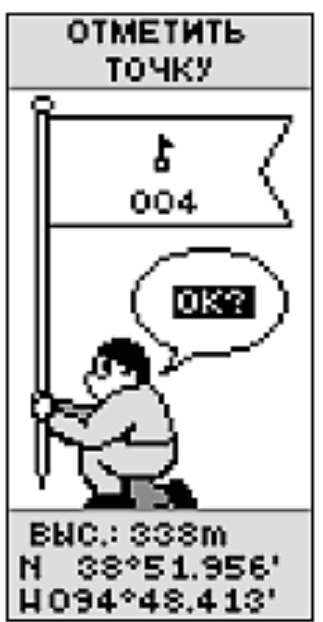

Рис. 2

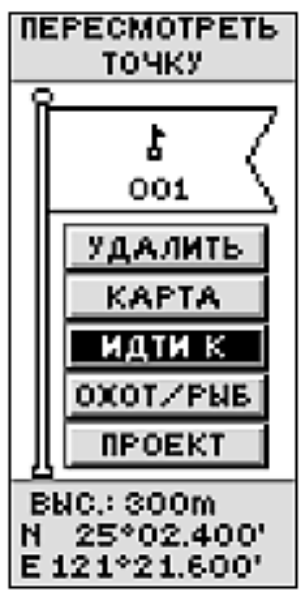

Рис. 3

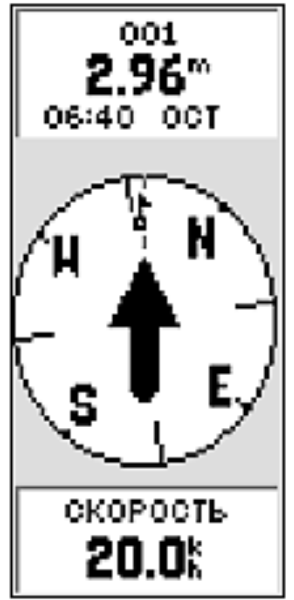

Рис. 4

Необходимо двигаться в направлении указателя, добиваясь того, чтобы указатель совпал с линией направления движения (верхняя точка шкалы компаса) (рис. 4). Во время движения на странице «указатель» кроме направления движении представлена информация о расстоянии до точки, скорости движения и времени, оставшимся до прибытия в пункт назначения.

При наличии топографической карты, по которой осуществляется прокладка маршрута движения, навигатор так же может облегчить поиск пути к 
намеченной цели. Для этого следует определить по карте географические координаты характерных точек маршрута (широту и долготу) и ввести их в навигатор. Далее через страницу «отметка» (рис. 1) отмечаем точку нахождения навигатора (рис. 2) и редактируем её перейдя через пункт меню «точки» (рис. 1) на страницу «пересмотр точки» (рис. 3), вводя новые название и координаты.

Кроме того, развитие компьютерных технологий и, прежде всего интернета, позволяет расширить возможности применения GPS-навигаторов. Если в поисковой системе «Google», задать название интересующего нас места, например набрав в строке поиска «Google» «озеро Сектинское», перейдя затем на страницу «карта» и далее на страницу «спутник», получим изображение озера по спутниковым снимкам (рис. 5).

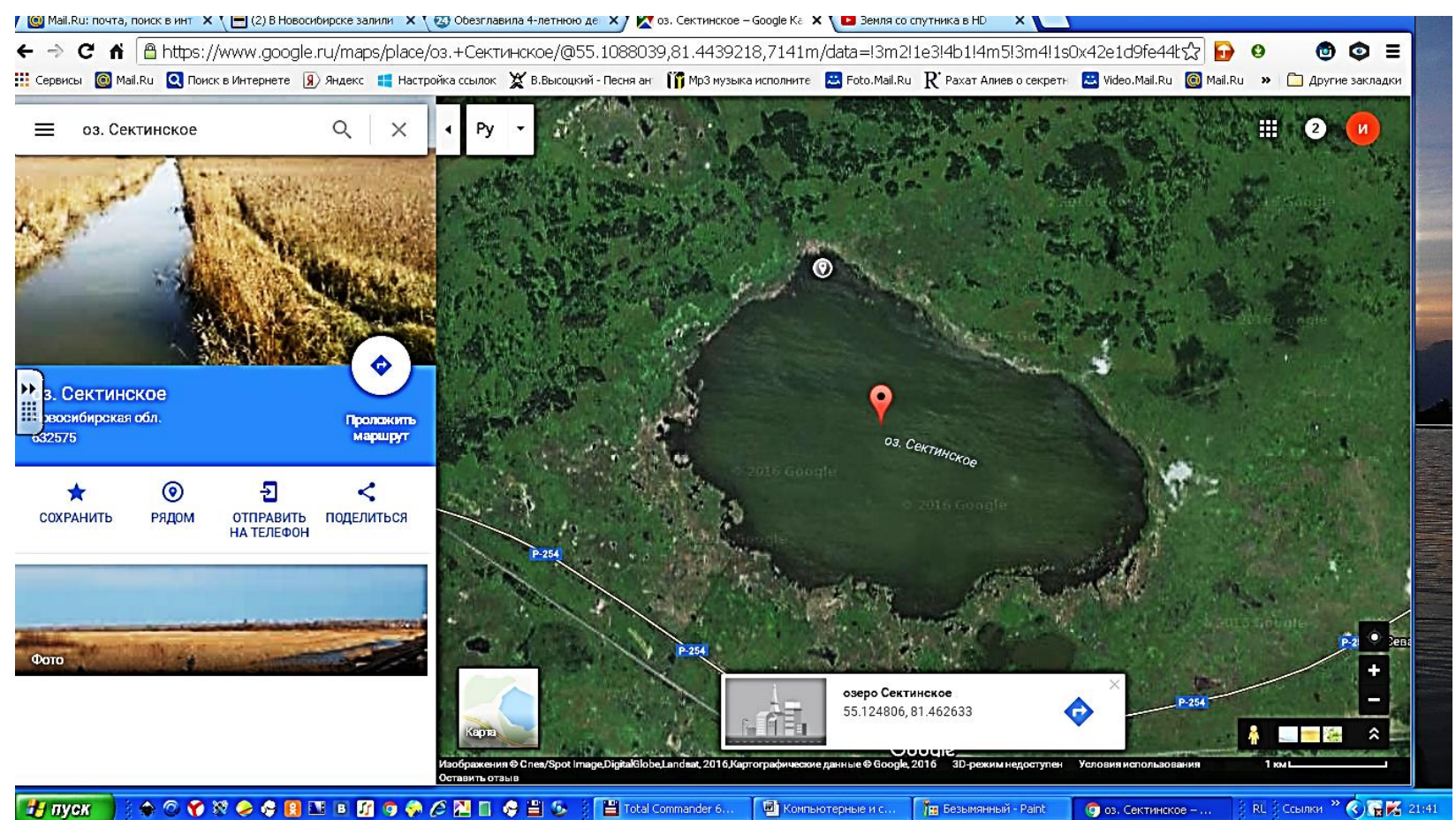

Рис. 5

С помощью кнопки «+» на экране монитора можно увеличить масштаб этого изображения, а наведя курсор на нужное место и нажав левую клавишу мыши определить координаты любой точки изображения, которые появляются на выпадающей панели внизу экрана. Координаты места наведения курсора (широта и долгота) выводятся в формате градусов с десятичными долями. В случае необходимости их следует перевести в градусы, минуты, секунды. Функция увеличения изображения позволяет лучше разглядеть детали изображения, найти 
интересные для вас подробности. Так, продолжая приводить примеры, связанные с озером Сектинское, рассмотрим увеличенный участок северо-западной части озера (рис. 6).

На нём отмечен хорошо видимый выход на берег в зарослях тростника. Занеся координаты этого места в виде точки в GPS-навигатор, можно затем легко его найти. Отмечая последовательный ряд характерных точек и, сохраняя их в памяти навигатора в виде маршрута, затем с помощью навигатора найдём путь к необходимому месту.

В заключение можно сказать, что подобное использование современных технологий позволяет значительно облегчить процесс передвижения по незнакомой, ненаселённой местности, а следовательно значительно уменьшить риск потери ориентировки и связанных с этим несчастных случаев. В случае использования автомобильного или водномоторного транспорта такая методика навигации позволяет экономить расход топлива и моторесурс. Также наши предложения могут использоваться и в профессиональной деятельности - геологами, геодезистами, топографами.

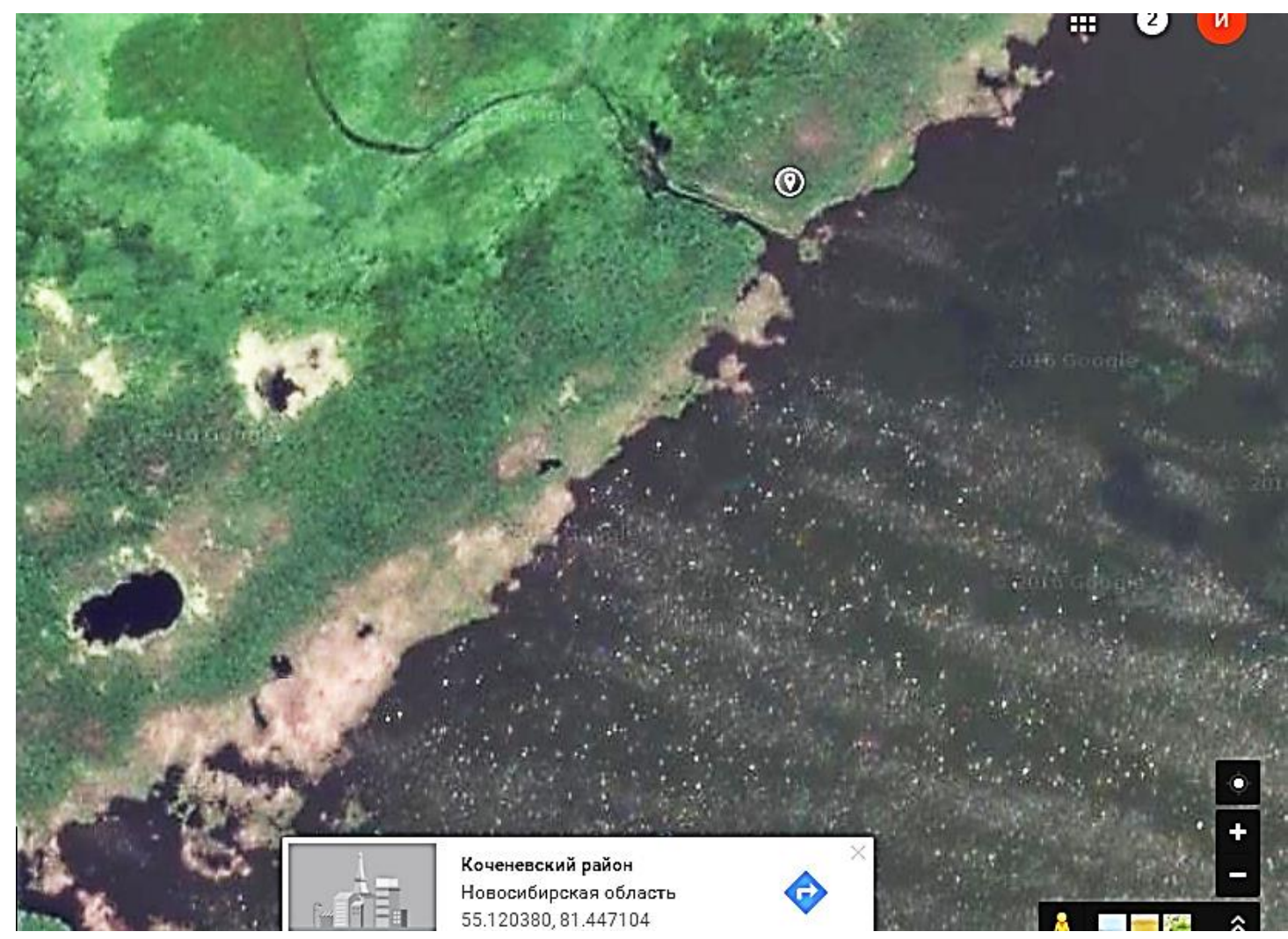

Рис. 6 


\section{Список литературы}

1. Навигация [Электронный ресурс]. - Режим доступа: https://ru.wikipedia.org/wiki/

2. Антонович К.М. Навигация [Текст] - Новосибирск: СГУГиТ, 2015. $233 \mathrm{c}$.

3. Антонович К.М. Использование спутниковых радионавигационных систем в геодезии [Текст]: Монография: в 2-х т. - М.: Картгеоцентр, 2005. - 334 с. T. 1.

4. Антонович К.М. Использование спутниковых радионавигационных систем в геодезии [Текст]: Монография в 2-х Т.- М.: Картгеоцентр.- 2006. 360 c. - T. 2.

5. Яценов B.C. Основы спутниковой навигации. Системы GPS NAVSTAR и ГЛОНАСС [Текст]. - М.: Горячая линия - Телеком, 2005. - 272 с.

6. Косарев Н.С. Исследование методики контроля фазовых ГНСС измерений по имитационным данным GPS [Текст] // Вестник СГГА. - 2016.Вып. 1 (33). - С. 6-13.

7. Шендрик Н.К. Результаты экспериментальных определений координат геодезического пункта по измерениям ГЛОНАСС [Текст] // Вестник СГГА. №32. -2015 . - C. 33-41.

8. Любич М.О. Оценка точности позиционирования с применением оборудования ГНСС компании JAVAD GNSS [Текст] / М.О. Любич, Д.И. Рычков // Геопрофи. - 2015. - №1. - С. 39-43.

9. Проблемы обеспечения точности координатно-временных определений на основе применения ГЛОНАСС-технологий [Текст] / А.С. Толстиков, В.А. Ащеулов, К.М. Антонович, Ю.В. Сурнин // Вестник СГГА. - 2012.Вып. 2 (18). - C. 3-11.

10. Косарев Н.С. Статистический анализ точности определения положений спутников систем ГЛОНАСС и GPS [Текст] / Н.С. Косарев, А.С. Щербаков // Вестник СГГА. - 2014. - Вып. 2 (26). - С. 9-18. 
11. Результаты исследований спутниковой геодезической аппаратуры по измерениям ГЛОНАСС [Текст] / А.П. Карпик, О.В. Твердовский, С.В. Середович, А.П. Решетов, А.А. Струков // Интерэкспо ГЕО-Сибирь-2015: XI Междунар. науч. конгр.: Междунар. науч. конф. «Геодезия, геоинформатика, картография, маркшейдерия»: Сб. материалов в 2 т., Новосибирск, 13-25 апреля 2015 г. - Новосибирск: СГУГиТ, 2015 - Т. 2. - С. 125-134.

12. Косарев Н.С. Восстановление фазы несущей: проблемы и пути решения [Текст] // Вестник СГГА. - 2012. - Вып. 1 (17). - С. 53-60.

13. Habrich H. Geodetic Applications of the Global Navigation Satellite System (GLONASS) and of GLONASS/GPS Combinations [Electronic resource] / H. Habrich. - 1999. - 147 p [Электронный ресурс]. - Режим доступа: http://www.ifag.de/misk_publ_idx.htm

14. Айфромович Э.Л. Погрешность позиционирования орбитальных потребителей спутниковых радионавигационных систем Э.Л. Айфромович, П.В. Татаринов // Исследовано в России. - 2005 [Электронный ресурс]. - Режим доступа: http://zhurnal.ape.relarn.ru/articles/2005/222.pdf.

15. Interface Control Document ICD - GPS 200 C. 10 Oct. 1993 - 14 Jan. Англ. - 2003. - 198 p. [Electronic resource]- Режим доступа: www.navcen.uscg.gov/.../gps/icd200/default.htm

16. Interface Control Document ICD-GALILEO-200C. 10 Oct. 1993 - 14 Jan. Англ. 2010. - 196 p. [Электронный ресурс]. - Режим доступа: http://ec.europa.eu/enterprise/policies/satnav/galileo/files/galileo-os-sis-icd-issue1revision1_en.pdf

17. Глобальная навигационная спутниковая система ГЛОНАСС. Интерфейс. контрол. док. (ред. 5.1). - М.: Координац. науч.-информ. центр ВКС России, 2008.- 74 с. [Электронный ресурс]. Режим доступа: http://www.glonasscenter.ru

18. RTKLIB ver. 2.4.2 Manual [Электронный ресурс].- Режим доступа: http://www.rtklib.com/prog/rtklib_2.4.2.zip 
19. Harris B. The GPSTk: an open source GPS toolkit / B. Harris, R. Mach [Текст] Англ. // Journal of GPS Solution, №. 2 - 2007 - Vol. 11. - P. 145-150.

20. Геодезическое обеспечение глобальной навигационной спутниковой системы ГЛОНАСС [Текст] / С.В. Козлов, А.Н. Зуева, Е.В. Новиков, Д.И. Плешаков, Т.Л. Сидорова-Бирюкова, В.Г. Жуков // Навигационные спутниковые системы, их роль и значение в жизни современного человека: Тез. докл. 2-й Междунар. науч.-техн. конф., посвящ. 30-летию запуска на орбиту первого навигац. космич. аппарата «Глонасс», 10-14 октября 2012 г., Железногорск / Под общ. ред. Н.А. Тестоедова; ОАО «Информационные спутниковые системы»; Сиб. гос. аэрокосмич. ун-т. - Красноярск, 2012. - С. 29-31.

21. Антонович К.М. Метод контроля кодовых и фазовых псевдодальностей в пространстве координат [Текст] / К.М. Антонович, Н.С. Косарев // Изв. вузов. Геодезия и аэрофотосъемка. - 2012. - №2/1. - С. 11-15.

22. Косарев Н.С. Алгоритм определения пространственных углов аэроразведочной платформы по измерениям трехантеного ГНСС комплекса [Текст] / Н.С. Косарев, С.О. Шевчук // Вестник СГГА. - 2013. - Вып. 4 (24). - С. 37-47.

23. Ганагина И.Г. Выбор ГНСС-аппаратуры для реализации точного позиционирования подвижных объектов [Текст] / И.Г. Ганагина, Н.С. Косарев, Р.Ф. Темирбулатов // Интерэкспо ГЕО-Сибирь-2014: Х Междунар. науч. конгр.: Междунар. науч. конф. «Геодезия, геоинформатика, картография, Новосибирск: 18 апреля 2014 г.). Маркшейдерия»: Сб. материалов в 2 т. - Новосибирск: СГГА, 2014. - T. 2. - C. 118-123.

24. Карпик А.П. Проблемы и перспективы точного позиционирования с использованием массовой аппаратуры потребителя ГНСС [Текст] / А.П. Карпик, Л.А. Липатников // Интерэкспо ГЕО-Сибирь - 2014: Х Междунар. науч. конгр.: Междунар. науч. конф. Геодезия, геоинформатика, картография, маркшейдерия, 18 апреля 2014 г.): Сб. материалов в 2 Т. (Новосибирск: СГГА, 2014. - Т. 2. C. $124-127$.

25. Garmin, Руководство пользователя [Электронный ресурс]. - Режим доступа https://www.garmin.com/ 
Глазунов Александр Сергеевич - канд. техн. наук, доцент кафедры физической геодезии и дистанционного зондирования ФГБОУ ВО «Сибирская государственная геодезическая академия», Россия, Новосибирск.

Glazunov Aleksandr Sergeevich - candidate of technical sciences, associate professor of the Department of Physical Geodesy and Remote Sensing FSBEI of HE "Siberia State Academy of Geodesy", Russia, Novosibirsk. 